\title{
Efficient scale of prefectural government in China
}

\author{
Mototsugu Fukushige ${ }^{\text {* }}$ and Yingxin $\mathrm{Shi}^{2}$
}

\author{
* Correspondence: \\ mfuku@econ.osaka-u.ac.jp \\ ${ }^{1}$ Graduate School of Economics, \\ Osaka University, 1-7, \\ Machikaneyama-cho, Toyonaka, \\ Osaka 560-0043, Japan \\ Full list of author information is \\ available at the end of the article
}

\begin{abstract}
Background: China has five layers of government including the central government. Recently, some prefectural governments meet fiscal distress.

Methods: We investigate the effects of urban and rural populations and area sizes on the expenditures of the prefecture-level local government by estimating quintile regression.
\end{abstract}

Results: At around 220,000 people, per capita local government expenditure for urban populations is minimized in our simulation. The expenditure for rural populations is proportional to the population size. The expenditure in accordance with the areas is also proportional to the area size.

Conclusions: The cost structure is the reason why China's recent rapid urbanization increases prefectural government's fiscal distress.

Keywords: Efficient scale, Local government, Quantile regression, China

JEL Classification: $\mathrm{H} 40, \mathrm{H} 72, \mathrm{R} 51$

\section{Background}

China has five layers of government including the central government. Each level of government, except the central government, receives financial transfers from the higher ranks of government and distributes the financial transfers to the lower levels of government. This system has operated since China's national foundation. As for the tax collection system, the tax contracting system changed to the tax sharing system in 1994. In addition to these tax collecting and intergovernmental financial transfer systems, there is another set of financial resources for each level of government, for example, several kinds of charges or rental fees. These are extrabudgetary revenues, and these finance the extrabudgetary expenditures for each level of government. There are several studies and explanations of this complex system. Ahmad (1997) reviews this system including its history, Bahl and Martinez-Vazquez (2006) summarize recent reforms to the system, and Man (2011) focuses on the local financial system.

Recently, urbanization in China has been rapid and nationwide. This trend has induced additional demand for public expenditure at each level of local government. Most prefectural governments face financial problems. Tsui (2005) investigated the effects of intergovernmental fiscal transfers on the equalization of fiscal expenditures across counties. To remove or reduce such financial distress, several researchers have suggested several kinds of reforms of local government fiscal

\section{Springer}

(c) 2016 Fukushige and Shi. Open Access This article is distributed under the terms of the Creative Commons Attribution 4.0 International License (http://creativecommons.org/licenses/by/4.0/), which permits unrestricted use, distribution, and reproduction in any medium, provided you give appropriate credit to the original author(s) and the source, provide a link to the Creative Commons license, and indicate if changes were made. 
systems or intergovernmental transfer systems; for example, the World Bank (2007) discussed the reforms to China's tax system and intergovernmental fiscal system and transfer totally, and Bahl (2011) examined decentralization and revenue assignment.

However, most studies have proposed changes to the intergovernmental financial transfer system or tax revenue systems. Few of them mention the adequacy of the fivelayer government system or optimal level or size of local government or local government's roles in providing public goods or services. Prefecture populations vary from 7000 to $2,239,000$, and prefecture areas vary from 86 to $198,318 \mathrm{~km}^{2}$. ${ }^{1}$ Some prefectures consist only of farmers, and others have relatively large urban populations. Additionally, there are some prefectural governments in metropolitan areas, including Tianjin and Shanghai. In such cases, it might be impossible to develop a reform that maintains the sizes or systems of prefectures. In this paper, to evaluate the adequacy of the five-layer local government system, we investigate the efficient scale of prefectures from a minimizing government expenditure viewpoint, using data from 2037 prefectures, which excludes some prefectures within metropolitan areas and missing observations.

Following several previous studies, we consider whether local government expenditures are determined by local population and area size. Most prefectures, however, are composed of both urban and rural areas, so we assume that local government expenditures depend on urban and rural populations and area size. We also assume that the total amount of government expenditures is determined by a quartic function of each factor. This assumption corresponds to the assumption that per capita expenditures is a cubic function. The reason why we assume a cubic function for per capita expenditures is that several previous studies assumed a U-shaped function for per capita expenditures for several public services or costs. Additionally, by allowing a nonsymmetrical U-shaped function for per capita expenditures in levels to capture the asymmetric marginal effects below and above the lowest (optimal) point, we assume a cubic function. ${ }^{2}$ In the estimation process, we find too much variation in per capita expenditures even when we control several factors, so we apply a quantile regression approach to the data. From the estimated results, we analyze the efficient scales for urban and rural populations and area size.

\section{Methods}

\section{Literature survey of efficient scale of local governments}

Oates (1972) examined fiscal federalism, and several subsequent studies investigated systems of local public finance. Some of these studies, such as Alesina and Spolare (2003), examined the optimal size of governments or nations. Other authors have discussed the optimal combination or layers of local governments, for example, Hochman et al. (1995) and Baleiras (2001). ${ }^{3}$ To investigate the real size of local governments, we must first examine the cost structures of local public services. The empirical analysis of Shelton (2007), which investigated the determinants of central and local governments' total expenditure and expenditures on some specific items using international data, focused on the optimal allocation of service provisions among central and local governments. 
Many papers have examined the cost structure or efficiency of providing local public services. Most of these studies attempt to investigate the cost structures of specific public services such as the police or fire department, schools, sewage, or water supply services and so on. For example, Hirsch (1959) investigated total expenditure on police services, refuse collection, fire protection, and education services. He fitted a quadratic function of population and found inverted U-shaped relationships with various kinds of expenditures, which suggest the existence of economies of scale. Bodkin and Conklin (1971) conducted a similar analysis on per capita local public expenditures. They found a U-shaped relationship between per capita total expenditure and population but did not find U-shaped relationships with some specific public expenditure items. Beaton (1974) fitted linear regression equations to the cost of police services by population size of cities. Borcherding and Deacon (1972) also fitted simple log-linear equations to several outputs of public services. Craig (1987), Craig and Heikkila (1989), and Edwards (1990) introduced congestion functions and estimated the degrees of congestion in providing public safety and others. Ladd (1992) estimated a piecewise linear function and obtained asymmetric U-shaped cost function. Solé-Ollé and Bosch (2005) took a similar approach. Duncombe et al. (1995) also found asymmetric relationships between school size and expenditures. Several studies have fitted quadratic functions to the cost structure of local public services: Hirsch (1965) for refuse collections, Knapp (1982) for crematoria, and Tao and Yuan (2005) for public elementary schools. Furthermore, in relation to other aspects of cost structures, Ladd (1994) and Nelson (1992) investigated the relationship between population growth and counties' expenditures. Carruthers and Ulfarsson (2003) investigated the effects of population growth and changes in population densities from the aspect of urban sprawl. Duncombe and Yinger (1993) extended this type of analysis to multiple types of public services and estimated the degree of economies of scope. Au and Henderson (2006) focused on the agglomeration effect of cities in China and estimated an inverted U-shaped function for productivity. ${ }^{4}$

When we estimate the cost structure of specific public services, we cannot determine the optimal size of the local government. However, this type of research provides evidence regarding which level or layer of government should supply police or other specific public services. When we estimate the total expenditure function, we can directly investigate the efficient scale of the local government. However, this type of analysis is limited by the existing roles of local government within the current central-local government system.

In this paper, we investigate the efficient scale of prefectural government; thus, our paper adopts the latter type of analysis. According to Martinez-Vazquez and Qiao (2011), prefectural government mainly provides services related to public security, social security, and health care within the current five-layer government system in China. As for the prefectural government's expenditure shares, the top four items are capital investment, education, government administration, and public security. We cannot obtain each prefecture's detailed fiscal expenditures. This is another reason why we cannot apply the former type of studies to some specific public services. In this paper, we assume that total prefectural expenditures also have U-shaped cost structures as do specific expenditures, e.g., public security, education or government administration. 


\section{Econometric model for aggregated data}

The details of local government expenditures are not available. We only have budgetary expenditures and extrabudgetary expenditures in total. Therefore, we investigate the determinants of total of budgetary and extrabudgetary expenditures $(G)$. We assume that this total expenditure consists of three components: expenditure for urban population $\left(G_{U}\right)$, expenditure for rural population $\left(G_{\mathrm{A}}\right)$, and expenditure related to area size $\left(G_{S}\right)$ :

$$
G=G_{U}+G_{\mathrm{A}}+G_{\mathrm{S}}
$$

Then, each of these three components is a quartic function of each factor:

$$
\begin{aligned}
& G_{\mathrm{U}}=\alpha_{0}+\alpha_{1} \text { UPop }+\alpha_{2} \text { UPop }^{2}+\alpha_{3} \text { UPop }^{3} \alpha_{4} \text { UPop }^{4}, \\
& G_{\mathrm{A}}=\beta_{0}+\beta_{1} \text { RPop }+\beta_{2} \text { RPop }^{2}+\beta_{3} \text { RPop }^{3}+\beta_{4} \text { RPop }^{4}, \\
& G_{\mathrm{S}}=\gamma_{0}+\gamma_{1} \text { Area }+\gamma_{2} \text { Area }^{2}+\gamma_{3} \text { Area }^{3}+\gamma_{4} \text { Area }^{4},
\end{aligned}
$$

Where UPop, RPop, and Area are urban population, rural population, and area size, respectively. ${ }^{5}$ We can write the equation for per capita expenditures as follows:

$$
\begin{aligned}
\frac{G}{\text { Pop }}= & \frac{\alpha_{0}}{\text { Pop }}+\alpha_{1} \frac{\mathrm{UPop}}{\text { Pop }}+\alpha_{2} \frac{\mathrm{UPop}^{2}}{\text { Pop }}+\alpha_{3} \frac{\mathrm{UPop}^{3}}{\text { Pop }}+\alpha_{4} \frac{\mathrm{UPop}^{4}}{\text { Pop }} \\
& +\frac{\beta_{1}}{\text { Pop }}+\beta_{1} \frac{\mathrm{RPop}}{\text { Pop }}+\beta_{2} \frac{\mathrm{RPop}^{2}}{\text { Pop }}+\beta_{3} \frac{\mathrm{RPop}^{3}}{\text { Pop }}+\beta_{4} \frac{\mathrm{RPop}^{4}}{\text { Pop }} \\
& +\frac{\gamma_{0}}{\text { Pop }}+\gamma_{1} \frac{\text { Area }}{\text { Pop }}+\gamma_{2} \frac{\text { Area }^{2}}{\text { Pop }}+\gamma_{3} \frac{\text { Area }^{3}}{\text { Pop }}+\gamma_{4} \frac{\text { Area }^{4}}{\text { Pop }}
\end{aligned}
$$

and this equation can be rewritten as

$$
\begin{aligned}
& \frac{G}{\text { Pop }}=\frac{\delta}{\text { Pop }}+\alpha_{1} \frac{\mathrm{UPop}}{\text { Pop }}+\alpha_{2} \frac{\mathrm{UPop}^{2}}{\text { Pop }}+\alpha_{3} \frac{\mathrm{UPop}^{3}}{\text { Pop }}+\alpha_{4} \frac{\mathrm{UPop}^{4}}{\text { Pop }} \\
& +\beta_{1} \frac{\text { RPop }}{\text { Pop }}+\beta_{2} \frac{\mathrm{RPop}^{2}}{\text { Pop }}+\beta_{3} \frac{\mathrm{RPop}^{3}}{\text { Pop }}+\beta_{4} \frac{\mathrm{RPop}^{4}}{\text { Pop }} \\
& +\gamma_{1} \frac{\text { Area }}{\text { Pop }}+\gamma_{2} \frac{\text { Area }^{2}}{\text { Pop }}+\gamma_{3} \frac{\text { Area }^{3}}{\text { Pop }}+\gamma_{4} \frac{\text { Area }^{4}}{\text { Pop }}
\end{aligned}
$$

using the following reparameterization:

$$
\delta=\alpha_{0}+\beta_{0}+\gamma_{0}
$$

The relation between total population (Pop) and urban and rural populations,

$$
\text { Pop }=\text { UPop }+ \text { RPop }
$$

leads to

$$
1=\frac{\text { UPop }}{\text { Pop }}+\frac{\text { RPop }}{\text { Pop }}
$$

and we can rewrite the equation and add the error term as 


$$
\begin{aligned}
\frac{G}{\text { Pop }}= & \alpha_{1}+\delta \frac{1}{\text { Pop }}+\alpha_{2} \frac{\mathrm{UPop}^{2}}{\text { Pop }}+\alpha_{3} \frac{\mathrm{UPop}^{3}}{\text { Pop }}+\alpha_{4} \frac{\mathrm{UPop}^{4}}{\text { Pop }} \\
+\left(\beta_{1}-\alpha_{1}\right) \frac{\text { RPop }}{\text { Pop }}+ & \beta_{2} \frac{\text { RPop }^{2}}{\text { Pop }}+\beta_{3} \frac{\text { RPop }^{3}}{\text { Pop }}+\beta_{4} \frac{\text { Rop }^{4}}{\text { Pop }} \\
& +\gamma_{1} \frac{\text { Area }}{\text { Pop }}+\gamma_{2} \frac{\text { Area }^{2}}{\text { Pop }}+\gamma_{3} \frac{\text { Area }^{3}}{\text { Pop }}+\gamma_{4} \frac{\text { Area }^{4}}{\text { Pop }}+u .
\end{aligned}
$$

Furthermore, we introduce a reparameterization of

$$
\phi=\beta_{1}-\alpha_{1}
$$

and an additional factor to determine the expenditures: number of towns or villages in each prefecture (NTowns). Finally, we obtain the estimation equation:

$$
\begin{aligned}
\frac{G}{\text { Pop }}=\alpha_{1}+\theta & \frac{\text { NTowns }}{\text { Pop }}+\delta \frac{1}{\text { Pop }}+\alpha_{2} \frac{\mathrm{UPop}^{2}}{\text { Pop }}+\alpha_{3} \frac{\mathrm{UPop}^{3}}{\text { Pop }}+\alpha_{4} \frac{\mathrm{UPop}^{4}}{\text { Pop }} \\
+ & \phi \frac{\text { RPop }}{\text { Pop }}+\beta_{2} \frac{\mathrm{RPop}^{2}}{\text { Pop }}+\beta_{3} \frac{\mathrm{RPop}^{3}}{\text { Pop }}+\beta_{4} \frac{\mathrm{RPop}^{4}}{\text { Pop }} \\
& +\gamma_{1} \frac{\text { Area }}{\text { Pop }}+\gamma_{2} \frac{\text { Area }^{2}}{\text { Pop }}+\gamma_{3} \frac{\text { Area }^{3}}{\text { Pop }^{3}}+\gamma_{4} \frac{\text { Area }^{4}}{\text { Pop }}+u .
\end{aligned}
$$

The reason why we introduce NTowns as an additional explanatory variable is that each prefecture makes fiscal transfers to towns or villages within the prefectures and each town or village has fixed costs associated with the provision of their public services. Of course, we can consider other variables to explain the per capita expenditures, e.g., prefectural government's export, human capital or per capita GDP. ${ }^{6}$ In the present paper, we focus on investigating the effects of rural and urban population and areas, so we do not include other variables as explanatory variables except NTowns. Also, we cannot obtain the export and human capital data of prefectures. In the following sections, we estimate this equation (1) by OLS or another estimation method.

\section{Results and discussion}

\section{Data and OLS estimation}

In this section, we report the estimation results of equation (1) by OLS. Before exploring the results, we describe the data used in this paper. We use data for 2037 prefectures in the estimation. The coverage and sample size in each province or municipality are shown in Table 1 . The coverage of our sample is $71.3 \%$ because we delete the data of prefectures within metropolitan areas and some missing data exist. We collect data for urban and rural populations and area size from the 2009 China County Statistical Yearbook and prefectures' budgetary and extrabudgetary expenditures $^{7}$ from the 2009 National Prefecture, City, County Fiscal Statistical Book. Summary statistics of the data are shown in Table 2. The measurement units of the data are as follows: $G$ is in 10,000 yuan; Pop, UPop, and RPop are in 10,000 people; Area is in square kilometers; and NTowns is in number of towns. Table 2 also shows the summary statistics for the transformed data.

Table 3 shows the results of the OLS estimation. Some coefficients are estimated as being statistically significant, whereas others are insignificant. The 
Table 1 Coverage of sample for each province or municipality

\begin{tabular}{|c|c|c|c|}
\hline Provinces and municipalities & Sample & Total & Coverage \\
\hline Beijing Municipality & 5 & 18 & 0.278 \\
\hline Tianjin Municipality & 4 & 16 & 0.250 \\
\hline Hubei Province & 138 & 172 & 0.802 \\
\hline Shanxi Province & 97 & 119 & 0.815 \\
\hline Inner Mongolia Autonomous Region & 81 & 101 & 0.802 \\
\hline Liaoning Province & 43 & 100 & 0.430 \\
\hline Jilin Province & 41 & 60 & 0.683 \\
\hline Heilongjiang Province & 65 & 128 & 0.508 \\
\hline Shanghai Municipality & 3 & 18 & 0.167 \\
\hline Jiangsu Province & 57 & 106 & 0.538 \\
\hline Zhejiang Province & 55 & 90 & 0.611 \\
\hline Anhui Province & 61 & 105 & 0.581 \\
\hline Fijian Province & 57 & 85 & 0.671 \\
\hline Jiangxi Province & 80 & 99 & 0.808 \\
\hline Shandong Province & 91 & 140 & 0.650 \\
\hline Henan Province & 107 & 159 & 0.673 \\
\hline Hubei Province & 66 & 103 & 0.641 \\
\hline Hunan Province & 84 & 122 & 0.689 \\
\hline Guangdong Province & 74 & 121 & 0.612 \\
\hline Guangxi Province & 81 & 109 & 0.743 \\
\hline Hainan Province & 16 & 20 & 0.800 \\
\hline Changing Municipality & 26 & 40 & 0.650 \\
\hline Sichuan Province & 139 & 181 & 0.768 \\
\hline Guizot Province & 76 & 88 & 0.864 \\
\hline Yunnan Province & 120 & 129 & 0.930 \\
\hline Tibet Autonomous Region & 72 & 73 & 0.986 \\
\hline Shaanxi Province & 86 & 107 & 0.804 \\
\hline Gansu Province & 75 & 86 & 0.872 \\
\hline Qinghai Province & 38 & 43 & 0.884 \\
\hline Ningxia Hui Autonomous Region & 13 & 22 & 0.591 \\
\hline Xinjiang Uygur Autonomous Region & 86 & 98 & 0.878 \\
\hline Total & 2037 & 2858 & 0.713 \\
\hline
\end{tabular}

is the number of observations used in this paper. "Coverage" is the coverage ratio of the sample to the total

coefficient of determination $\left(R^{2}\right)$ is 0.49 . This is relatively high for this type of cross-sectional data analysis. However, tests for heteroskedasticity (LM-hetero) and misspecification (RESET) imply misspecification or crucial heteroskedasticity. Jarque-Bera's test for nonnormality of the error terms implies that the distribution of error terms cannot be normal. Robust $t$ values are estimated $t$ values calculated by White's heteroskedasticity-consistent standard errors. The calculated standard $t$ values and robust $t$ values are different, so these results also suggest the existence of heteroskedasticity in the error terms. Then, we plot the fitted values of the regression equation and residuals in Fig. 1 to check the distribution of the error terms. This figure implies that the error terms are asymmetric and 
Table 2 Summary statistics

\begin{tabular}{lcccc}
\hline Variables & Mean & Standard deviation & Minimum & Maximum \\
\hline Original data & & & & \\
G & 118863.8 & 104488.1 & 300 & 1504195 \\
Pop & 47.31635 & 34.89929 & 0.7 & 223.9 \\
RPop & 38.76117 & 30.29445 & 0.1 & 193.6 \\
Area & 4294.808 & 9945.455 & 86 & 198318 \\
NTowns & 14.70201 & 7.995951 & 1 & 72 \\
Transformed data & & & & \\
$\frac{G}{\text { Pop }}$ & 3363.36 & 2814.228 & 34.09091 & 34087.64 \\
$\frac{1}{\text { Pop }}$ & 0.054245 & 0.10624 & 0.004466 & 1.42857 \\
$\frac{\text { UPop }}{\text { Pop }}$ & 0.20093 & 0.14346 & 0 & 0.99342 \\
$\frac{\text { RPop }}{\text { Pop }}$ & 0.79907 & 0.14346 & 0.006579 & 1 \\
$\frac{\text { Area }}{\text { Pop }}$ & 644.5605 & 4058.228 & 2.56667 & 85662.23 \\
$\frac{\text { NTowns }}{\text { Pop }}$ & 0.5652 & 0.76666 & 0.031646 & 8.57143 \\
\hline
\end{tabular}

heteroskedastic. Some of the residuals imply the existence of outliers. A similar result is found in Solé-Ollé and Bosch (2005), Figure 2, p. 354. They dealt with this type of problem by applying a piecewise linear regression model. In this paper, we apply a quantile regression in the next section.

\section{Quantile regression approach}

A well-known text on quantile regression is Koenker (2005). This method is usually applied when the error term has heteroskedasticity with respect to the levels of the dependent

Table 3 Estimation results by OLS

\begin{tabular}{|c|c|c|c|}
\hline & Coefficient & $t$ value & Robust $t$ value \\
\hline Constant & 19860.4 & 23.842 & 10.526 \\
\hline$\frac{\text { NTowns }}{\text { Pop }}$ & 1002.82 & 7.980 & 4.573 \\
\hline$\frac{1}{P o p}$ & 115.802 & 0.090 & 0.005 \\
\hline$\frac{U P O D^{2}}{P O P}$ & -1621.85 & -13.424 & -6.543 \\
\hline$\frac{U P O p^{3}}{P O P}$ & 56.5807 & 10.917 & 5.849 \\
\hline$\frac{U P O D^{4}}{P O P}$ & -0.57576 & -9.4678 & -5.485 \\
\hline$\frac{R P O P}{P O P}$ & -19200.8 & -18.218 & -8.712 \\
\hline$\frac{R P O P^{2}}{P O P}$ & 0.095896 & 0.006 & 0.003 \\
\hline$\frac{R P O P^{3}}{P O P}$ & 0.084069 & 0.387 & 0.273 \\
\hline$\frac{R P O P^{4}}{P O P}$ & -0.00066 & -0.710 & -0.637 \\
\hline$\frac{A r e a}{\text { Pop }}$ & 0.178648 & 1.580 & 0.051 \\
\hline$\frac{\text { Area }^{2}}{\text { Pop }}$ & $-2.5 \mathrm{E}-06$ & -0.777 & -0.021 \\
\hline$\frac{A^{A r e a^{3}}}{P O p}$ & $2.58 \mathrm{E}-11$ & 0.810 & 0.021 \\
\hline$\frac{\text { Area }^{4}}{\text { Pop }}$ & $-8.9 \mathrm{E}-17$ & -0.960 & -0.024 \\
\hline $\operatorname{Adj} R^{2}$ & & 0.4987 & \\
\hline LM-hetero & & 85.507 & \\
\hline RESET & & 52.927 & \\
\hline Jarque-Bera & & 75719.2 & \\
\hline
\end{tabular}

Adj $R^{2}$, LM-hetero, RESET, and Jarque-Bera are adjusted $R^{2}$, test for heteroskedasticity, RESET test with squared fitted values, and Jarque-Bera test for normality. Italicized values mean statistically significant at the $5 \%$ level 


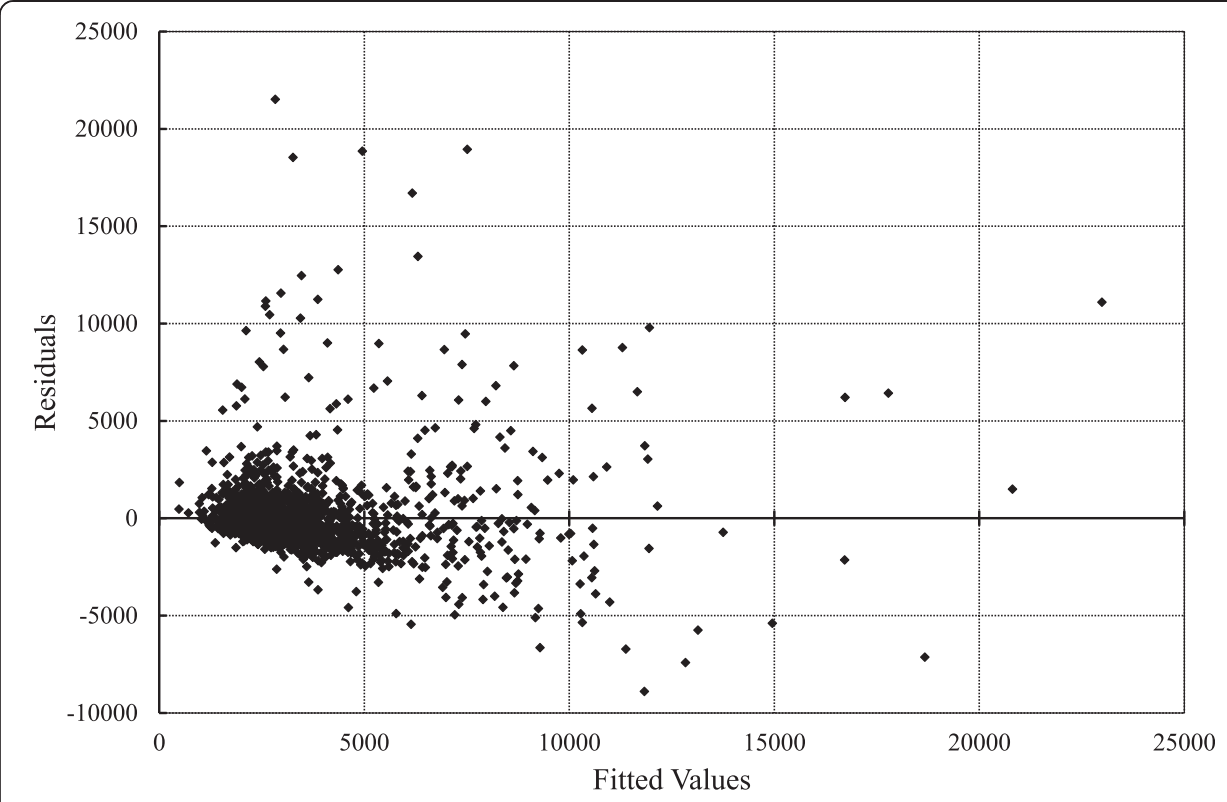

Fig. 1 Fitted values and residuals

variables. In this paper, we apply this method to multiple regression models with a quartic function. Details of this procedure are available in Koenker (2005); however, to summarize this method, we assume a linear regression model with an error term as follows:

$$
y_{i}=\mathrm{X}_{i}^{\prime} \beta+\varepsilon_{i,}, \quad i=1,2,3, \ldots, N .
$$

When we estimate the OLS estimator, we minimize the following objective function:

$$
S(\beta)=\sum_{i=1}^{N}\left(y_{i}-X_{i}^{\prime} \beta\right)^{2}
$$

As for the quantile regression, we set a quantile $\mu_{q}$ and $q$ as follows:

$$
q=\operatorname{Pr}\left(y_{i} \leq \mu_{q}\right)=F_{y}\left(\mu_{q}\right),
$$

where $F_{y}\left(\mu_{q}\right)$ is the distribution function of $y_{i}$. Of course, the inverse function of $F_{y}\left(\mu_{q}\right)$ means

$$
\mu_{q}=F_{y}^{-1}(q)
$$

If we assume $y_{i}=X_{i}^{\prime} \beta+\varepsilon_{i}$, this inverse function could be rewritten in terms of conditional probability as follows:

$$
\mu_{q}(X)=F_{y \mid X}^{-1}(q) .
$$

To estimate $\beta_{q}$ in a quantile regression requires minimization of the following objective function with respect to $\beta_{q}$ : 


$$
S\left(\beta_{q}\right)=\sum_{i: y_{i} \geq X_{i}^{\prime} \beta}^{N} q\left|y_{i}-X_{i}^{\prime} \beta_{q}\right|+\sum_{i: y_{i}<X_{i}^{\prime} \beta}^{N}(1-q)\left|y_{i}-X_{i}^{\prime} \beta_{q}\right| .
$$

This is a variation of least absolute deviation (LAD) estimation. There exist various methods to estimate the standard errors of the estimated parameters. In this paper, we use the LAD command in TSP version 5.0. This command estimates the standard errors of the coefficient using a bootstrap method with 500 replications.

The results of the quantile regression when we estimate eq. (1) with $q=0.1,0.25$, 0.5, 0.75, and 0.9 are shown in Table 4. The results show that some coefficients are not statistically significant at the $5 \%$ level in all settings of $q$, so we remove the corresponding variables from the equation and re-estimate the model. The results are shown in Table 5 as the selected model. This table shows the OLS estimation results using the same list of explanatory variables. Before going into the simulation analysis, we should mention about the possible meanings of a variation according to the setting of $q$. In the present paper, we do not include the per capita GDP or other variables as explanatory variables in regression equation. The effects from these variables present in the error terms and are estimated as a variation according to the setting of $q$. In the next section, using these results, we simulate the effects of UPop, RPop, and Area on ${ }^{G} /$ Pop. This type of simulation makes the robustness of the existence of the efficient scales.

\section{Simulation for efficient scales}

To simulate the effects of changes in the explanatory variables in the multiple regression equation, we should control all explanatory variables other than the variable of focus. In this section, we investigate the effects of UPop, RPop, and Area on ${ }^{G} /{ }^{\text {Pop }}$.

Table 4 Estimation results by quantile regression: full model

\begin{tabular}{|c|c|c|c|c|c|}
\hline Quantiles & 0.10 & 0.25 & 0.5 & 0.75 & 0.90 \\
\hline Constant & 8437.364 & 10865.07 & 14691.87 & 18867.71 & 25474.17 \\
\hline$\frac{\text { NTowns }}{\text { Pop }}$ & 186.2419 & 200.8443 & 472.8929 & 1246.982 & 2323.414 \\
\hline$\frac{1}{P O D}$ & 2790.369 & 2072.114 & 1612.773 & -256.541 & -2870.05 \\
\hline$\frac{U P O p^{2}}{P O P}$ & -582.815 & -790.664 & -1124.87 & -1489.6 & -2170.34 \\
\hline$\frac{U P O P^{3}}{P O P}$ & 17.69066 & 25.17713 & 37.11554 & 52.52024 & 88.6423 \\
\hline$\frac{U P D^{4}}{P O P}$ & -0.1602 & -0.24401 & -0.36007 & -0.5324 & -0.96903 \\
\hline$\frac{R P O p}{P o p}$ & -6867.2 & -9253.76 & -13284.8 & -17565.5 & -24829.6 \\
\hline$\frac{R P O p^{2}}{P O P}$ & -25.0469 & -22.1984 & -14.4934 & -13.016 & 7.5451 \\
\hline$\frac{R P O P^{3}}{P O P}$ & 0.27828 & 0.22899 & 0.12407 & 0.16248 & 0.016699 \\
\hline$\frac{R P O p^{4}}{P O P}$ & -0.00109 & -0.00086 & -0.00042 & -0.00069 & -0.00042 \\
\hline$\frac{\text { Area }}{\text { Pop }}$ & 0.12069 & 0.29961 & 0.4339 & 0.43212 & 0.36434 \\
\hline$\frac{A_{r e a}^{2}}{P_{o p}}$ & $-2.17 \mathrm{E}-06$ & $-4.66 \mathrm{E}-06$ & $-7.83 E-06$ & $-8.46 E-06$ & $-7.46 \mathrm{E}-06$ \\
\hline$\frac{\text { Area }^{3}}{\text { Pop }}$ & $8.35 E-12$ & $1.92 \mathrm{E}-11$ & $4.93 E-11$ & $9.98 E-11$ & $8.28 \mathrm{E}-11$ \\
\hline$\frac{\text { Area }}{\text { Pop }}$ & 1.17E-17 & $-5.10 \mathrm{E}-18$ & $-9.84 E-17$ & $-3.44 E-16$ & $-2.85 E-16$ \\
\hline Adj $R^{2}$ & 0.46307 & 0.47224 & 0.48437 & 0.48294 & 0.47717 \\
\hline
\end{tabular}

Adj $R^{2}$ is adjusted $R^{2}$. Italicized values mean statistically significant at the $5 \%$ level 
Table $\mathbf{5}$ Estimation results by quantile regression: selected model

\begin{tabular}{|c|c|c|c|c|c|c|}
\hline Quantiles & 0.10 & 0.25 & 0.5 & 0.75 & 0.90 & OLS \\
\hline Constant & 9865.556 & 12879.36 & 16433.2 & 19494.19 & 23919.46 & 19595.94 \\
\hline$\frac{\text { NTowns }}{\text { Pop }}$ & 372.7542 & 310.7989 & 594.6125 & 1329.612 & 2163.313 & 980.2919 \\
\hline$\frac{1}{P o p}$ & 2965.341 & 3612.943 & 1550.574 & 1299.058 & -3512.63 & 5.34297 \\
\hline$\frac{U P O P^{2}}{P O P}$ & -708.287 & -1004.27 & -1298.16 & -1540.59 & -1887.98 & -1590.68 \\
\hline$\frac{U P O p^{3}}{P O P}$ & 20.67388 & 32.16626 & 42.61537 & 53.8526 & 76.49473 & 55.56158 \\
\hline$\frac{U P p^{4}}{P O P}$ & -0.18161 & -0.31268 & -0.41115 & -0.54328 & -0.83928 & -0.56619 \\
\hline$\frac{R P O P}{P O P}$ & -9113.59 & -12080.4 & -15627.1 & -18605.9 & -22888.9 & -18819.8 \\
\hline $\begin{array}{l}\text { Area } \\
\text { Pop }\end{array}$ & 0.12268 & 0.18421 & 0.39747 & 0.27226 & 0.44509 & 0.19418 \\
\hline$\frac{\text { Area }^{2}}{\text { Pop }}$ & $-2.88 \mathrm{E}-06$ & $-2.83 \mathrm{E}-06$ & $-7.61 E-06$ & $-4.83 \mathrm{E}-06$ & $-7.99 \mathrm{E}-06$ & $-2.9 \mathrm{E}-06$ \\
\hline$\frac{\mathrm{Area}^{3}}{P_{o p}}$ & $1.73 \mathrm{E}-11$ & $9.67 E-12$ & $4.85 E-11$ & $6.95 E-11$ & $8.22 \mathrm{E}-11$ & $2.84 \mathrm{E}-11$ \\
\hline$\frac{\text { Area }^{4}}{\text { Pop }}$ & $-1.77 \mathrm{E}-17$ & 8.49E-18 & $-9.67 E-17$ & $-2.65 E-16$ & $-2.77 \mathrm{E}-16$ & $-9.6 \mathrm{E}-17$ \\
\hline$R^{2}$ & 0.46899 & 0.4791 & 0.48777 & 0.48514 & 0.47876 & 0.50135 \\
\hline
\end{tabular}

Italicized values mean statistically significant at the $5 \%$ level

For the former two populations, we assume a situation in which all the people in the prefectures live either in the urban or in the rural area: Pop = UPop or Pop = RPop.

First, we simulate the effects of urban population assuming Pop = UPop and setting the area and number of towns or villages under each prefecture at their average values: Area $=\overline{\text { Area }}$ and NTowns $=\overline{\text { NTowns }}$. Then, we calculate the effect of urban population on the per capita government expenditures corresponding to the changes in population as follows:

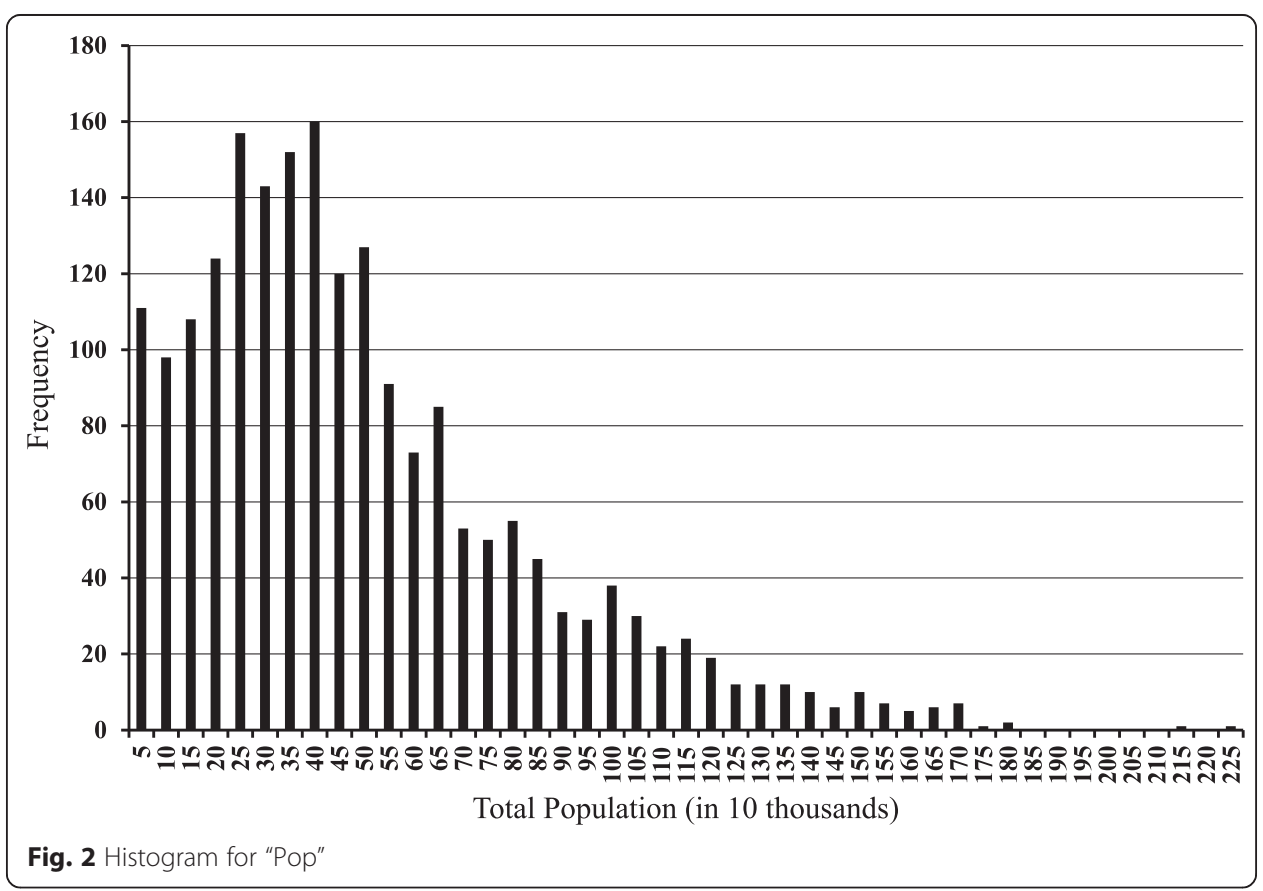




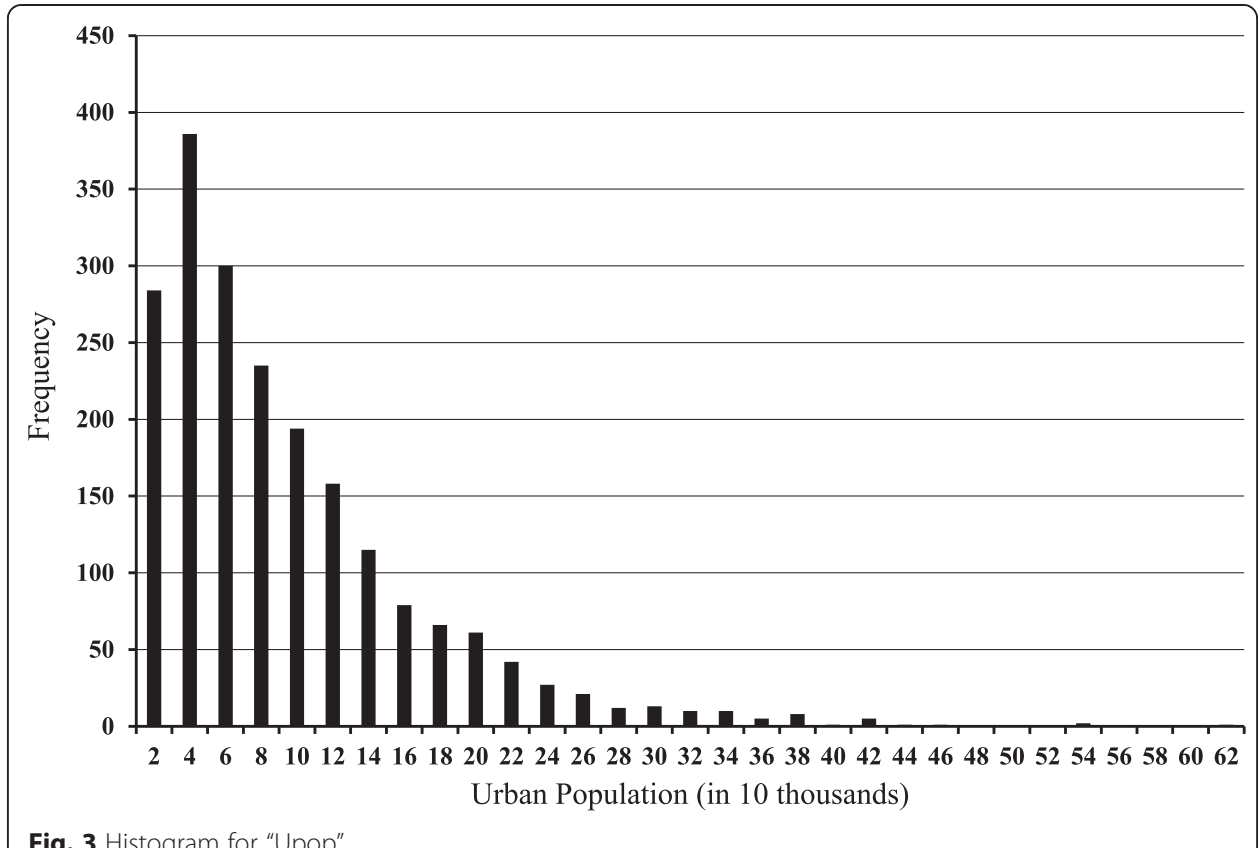

Fig. 3 Histogram for "Upop"

$$
\begin{aligned}
& \frac{\hat{G}}{P o p}(\text { Pop })=\hat{\alpha_{1}}+\hat{\theta} \frac{\overline{N T o w n s}}{\text { Pop }}+\hat{\delta} \frac{1}{P o p}+\hat{\alpha_{2} P o p}+\hat{\alpha_{3} P_{o p}}+\hat{\alpha_{4} P o p^{3}} \\
& +\hat{\gamma_{1}} \frac{\overline{\text { Area }}}{\text { Pop }}+\hat{\gamma_{2}} \frac{\overline{\text { Area }^{2}}}{\text { Pop }}+\hat{\gamma_{3}} \frac{\overline{\text { Area }^{3}}}{\text { Pop }}+\hat{\gamma_{4}} \frac{\overline{\text { Area }^{4}}}{\text { Pop }},
\end{aligned}
$$

where the parameters with hats are estimates and the variables with upper bars are average values. While the distribution of total populations ranges between zero and

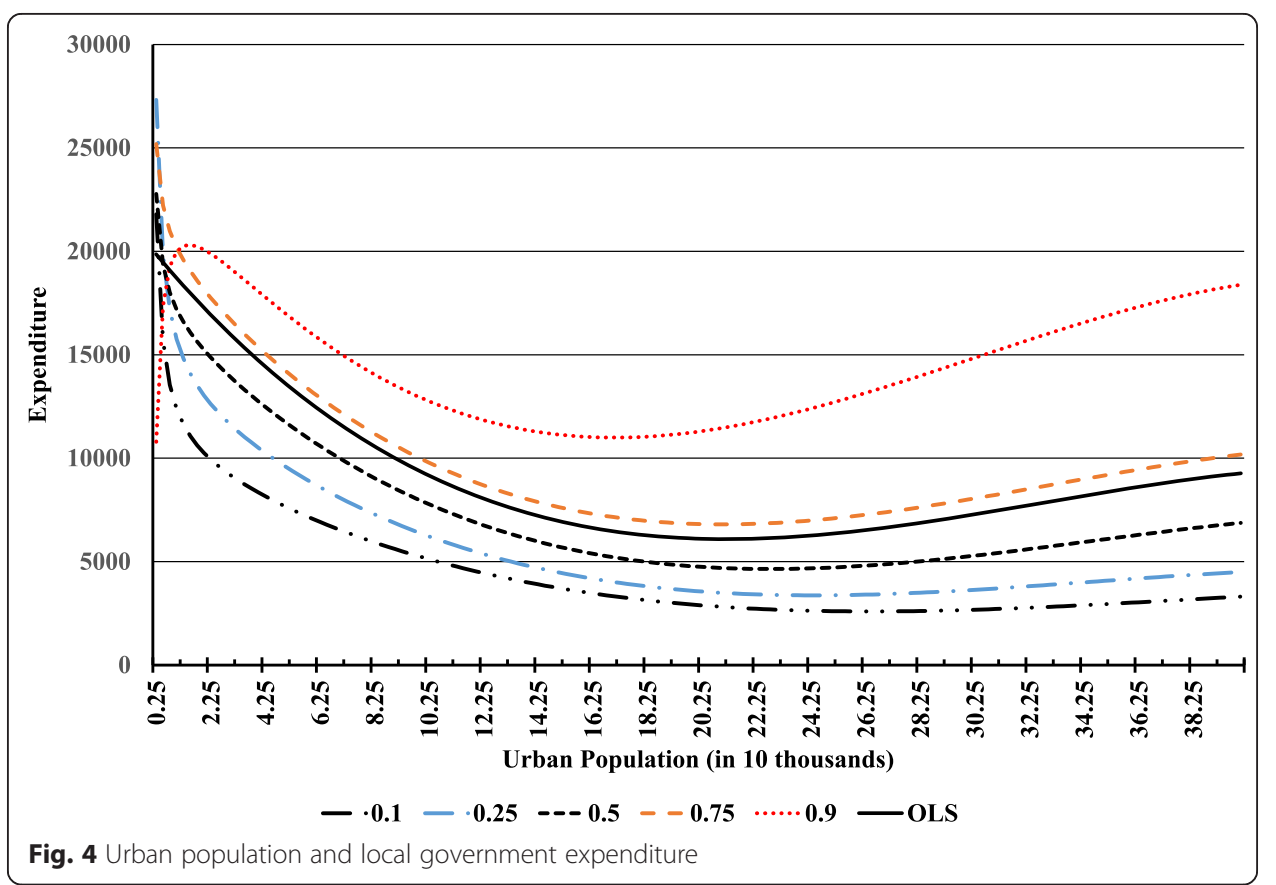


2,250,000 people (Fig. 2), urban populations are distributed between zero and 620,000 people (Fig. 3). Therefore, we figure the calculated per capita expenditures from 2550 to 400,000 people in Fig. 4. From this figure, we can observe that there exist the points to minimize the per capita expenditures in all the regression results: OLS, quantile regressions with $q=0.1,0.25,0.5,0.75$, and 0.9. The calculated points that minimize per capita expenditures are as follows:

$\begin{array}{lll}\text { OLS } & : & 212,000 \\ q=0.1 & : & 264,500 \\ q=0.25 & : & 243,500 \\ q=0.5 & : & 237,500 \\ q=0.75 & : & 210,000 \\ q=0.9 & : & 170,500 .\end{array}$

There exists a variation according to the setting of $q$, but it is located between 170,000 and 270,000 people. In particular, for the $q=0.5$ and OLS cases, the points are located mainly around 220,000 people. These results suggest that there is a most efficient scale for the urban population and it is located around 220,000 people. This variation according to the setting of $q$ may be caused by the interaction effect between omitted variables and error term in the equation. If $q$ goes to zero asymptotically, this method becomes similar to that of corrected least square (COLS) in econometrics for efficiency and productivity. ${ }^{8}$ Therefore, if we assume that the case of $q=0.1$ is the lower $10 \%$ efficient prefectures results, the most efficient prefectures minimize their expenditures when their urban populations are equal to or greater than 264,500 people.

Second, we simulate the effects of the rural population assuming Pop = APop and setting the area and number of towns or villages in each prefecture at their average values: Area $=\overline{\text { Area }}$ and NTowns $=\overline{\text { NTowns }}$. Then, we calculate the effect of the

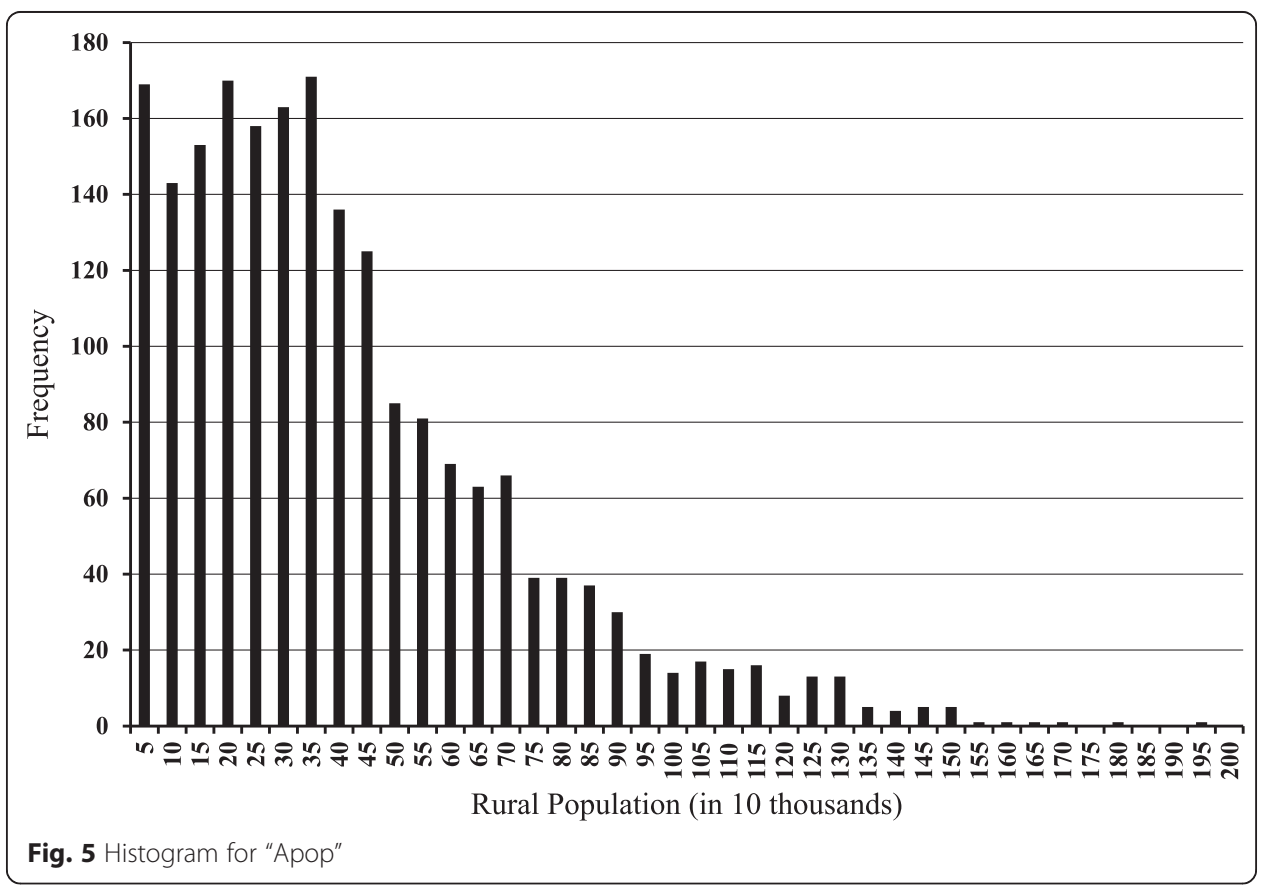




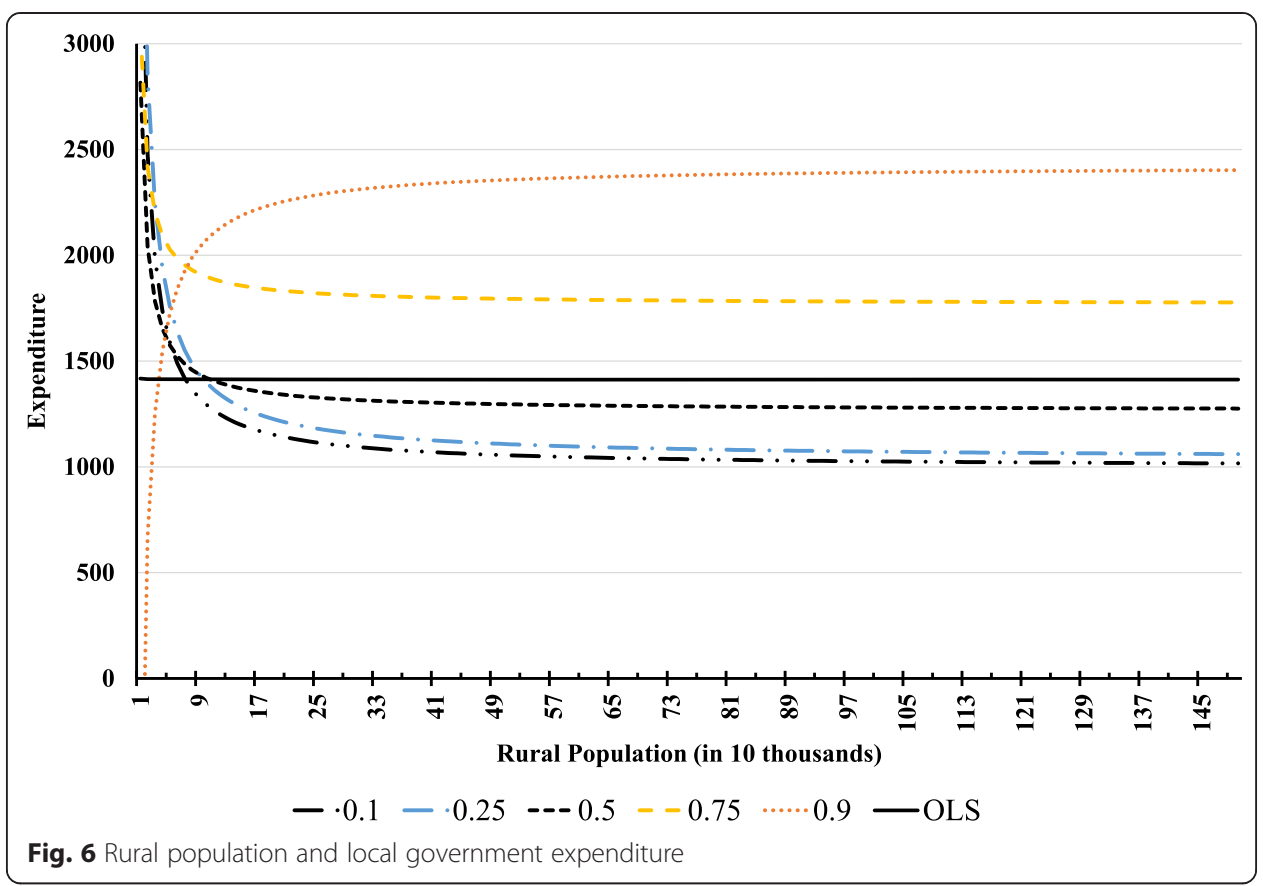

rural population on per capita government expenditures when the population changes as follows:

$$
\begin{aligned}
& \frac{\hat{G}}{P o p}(P o p)=\hat{\alpha_{1}}+\hat{\theta} \frac{\overline{N T o w n s}}{P o p}+\hat{\delta} \frac{1}{P o p}+\hat{\phi}+\hat{\beta_{2} P o p}+\hat{\beta}_{3} P_{o p}{ }^{2}+\hat{\beta}_{4} P o p^{3} \\
& +\hat{\gamma_{1}} \frac{\overline{\text { Area }}}{\text { Pop }}+\hat{\gamma_{2}} \frac{\overline{\text { Area }^{2}}}{\text { Pop }}+\hat{\gamma_{3}} \frac{\overline{\text { Area }^{3}}}{\text { Pop }}+\hat{\gamma_{4}} \frac{\overline{\text { Area }^{4}}}{\text { Pop }} \text {. }
\end{aligned}
$$

Rural population distributes between zero and 1,950,000 people (Fig. 5). Therefore, we figure the calculated per capita expenditures from 10,000 to $1,500,000$ people in Fig. 6. In this figure, some simulated lines cross in the range between 10,000 and 100,000 people; this phenomenon is caused by fixing the number of towns or villages under each prefecture at their average values, Area $=\overline{\text { rea }}$ and NTowns $=$ NTowns, with estimated coefficients for the higher-order quartic equation being statistically insignificant. Therefore, we do not investigate small rural population cases. When the population is 100,000 and over, per capita expenditures are slightly decreasing when $q$ $=0.1,0.25,0.5$, and 0.75 and slightly increasing when $q=0.95$, and flat in the OLS case. These results suggest that government expenditures for rural populations vary in proportion to population size. However, its effects are very small, so per capita government expenditures for rural population are almost constant. In other words, total government expenditures are proportional to rural population. Furthermore, we should pay attention to the simulated level of expenditures. Comparing the simulated expenditures for rural populations with those for urban populations, we see the former are much smaller than the latter. For example, the former are about 1300 yuan, whereas the latter do not fall below 5000 yuan in the $q=0.5$ case. This means that the prefectural government that governs a rural population operates cost-effectively. 
Third, we simulate the effects of area holding the ratios of urban population and rural population to total population at their average values: UPop $/$ Pop $=\overline{\text { UPop } / \text { Pop }}$ and $\mathrm{APop} /$ Pop $=\overline{\mathrm{APop} / \mathrm{Pop}}$, and the number of towns or villages in each prefecture at their average values, NTowns $=\overline{\text { NTowns }}$. Then, we calculate the effect of area on per capita government expenditures corresponding to changes in area as follows:

$$
\begin{aligned}
& \frac{\hat{G}}{\text { Pop }}(\text { Area }) \\
& =\hat{\alpha_{1}}+\hat{\theta} \frac{\overline{N T o w n s}}{P o p}+\overline{\hat{\delta} \frac{1}{P o p}}+\hat{\alpha_{2}} \frac{\overline{U P o p^{2}}}{P o p}+\hat{\alpha_{3} \frac{\overline{U P o p}}{P o p}} \\
& +\hat{\alpha_{4}} \frac{\overline{U P o p^{4}}}{P o p}+\hat{\phi} \frac{\overline{R P o p}}{P o p}+\hat{\beta_{2}} \frac{\overline{R P o p^{2}}}{P o p}+\hat{\beta_{3} \frac{R P^{2} p^{3}}{P o p}} \\
& +\hat{\beta_{4}} \frac{\overline{R P o p^{4}}}{P o p}+\hat{\gamma_{1}} \frac{\text { Area }}{\text { Pop }}+\hat{\gamma_{2}} \frac{\text { Area }^{2}}{\text { Pop }}+\hat{\gamma_{3}} \frac{\text { Area }^{3}}{\text { Pop }}+\hat{\gamma_{4}} \frac{\text { Area }^{4}}{\text { Pop }} \text {. }
\end{aligned}
$$

Area is distributed between zero and over $20,000 \mathrm{~km}^{2}$ (Fig. 7). Therefore, we calculate per capita expenditures from 389 to $16,000 \mathrm{~km}^{2}$ in Fig. 8 . The results indicate that per capita expenditures are increasing slightly in all cases but at a slow rate. These results suggest that government expenditures corresponding to area are almost constant.

\section{Conclusions}

We investigated the effects of urban and rural populations and area size on the expenditures of the prefectural-level local government. Throughout the empirical investigation, we found the following three results. First, at around 220,000 people, per capita local government expenditure for urban populations has a minimum value in our simulation. This can also be seen in the simulation results from the quantile regression.

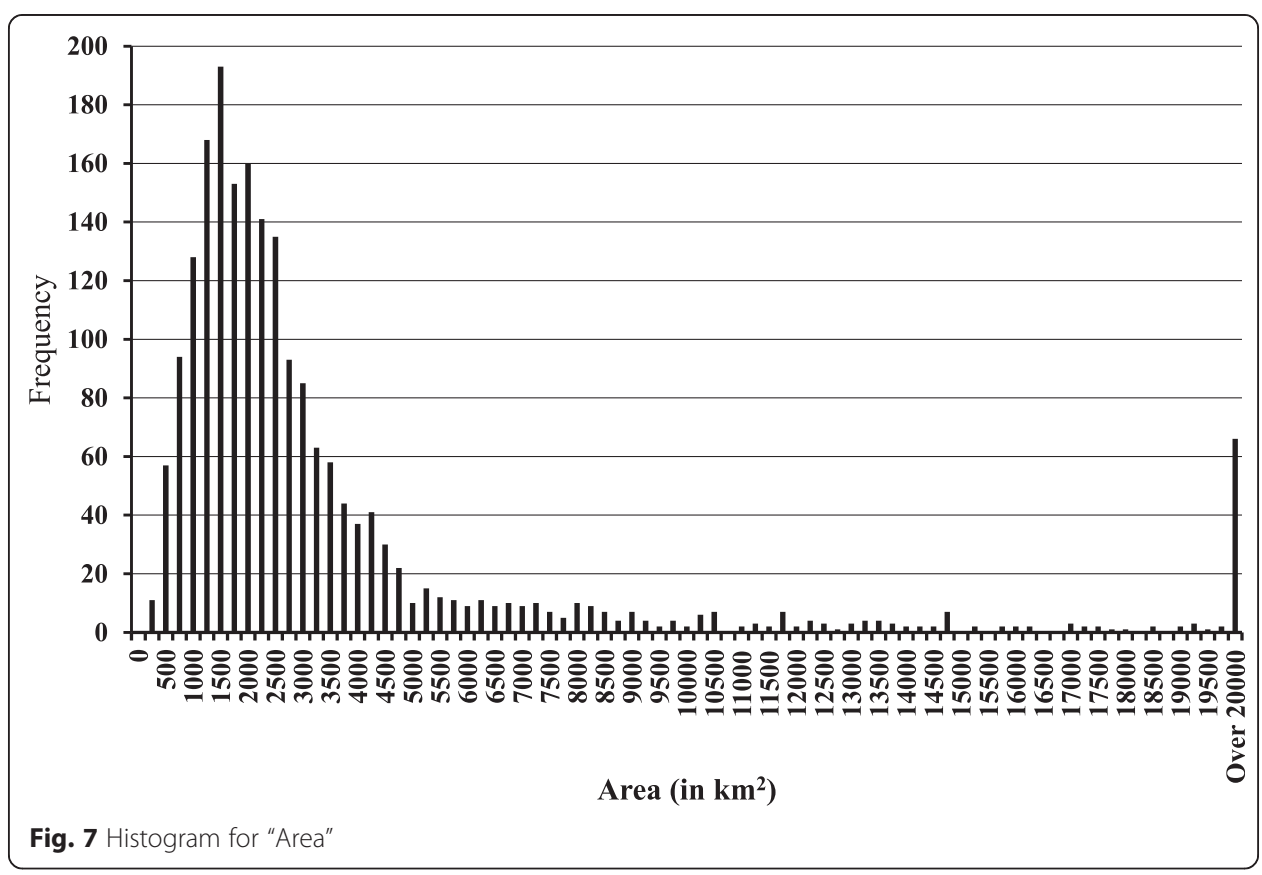




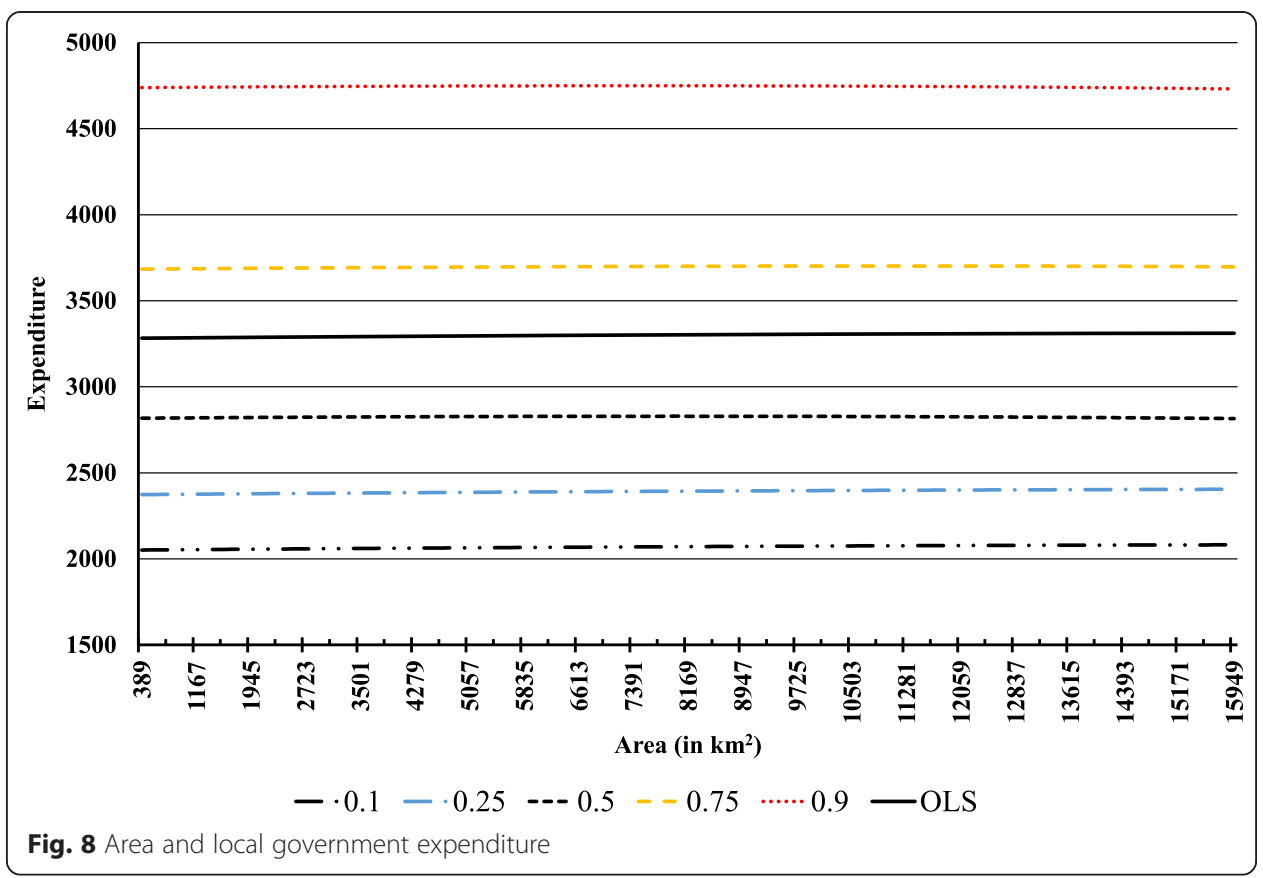

Second, expenditure for rural populations is proportional to population size. Additionally, per capita expenditures are much lower than those for urban populations. Third, per capita expenditures corresponding to area are almost constant. The last two findings mean that the expenditures are proportional only to population when all the prefectural populations are rural. If we consider these results from another viewpoint, China's recent rapid urbanization has increased prefectural government expenditures substantially. It has also caused fiscal distress among prefectural governments. Lichtenberg and Ding (2009) also discussed the present trend of land conversion from rural to urban use and the associated problems.

It is of course impossible to stop the current urbanization trend in China. However, prefectures that are heavily urbanized should be divided into prefectures of efficient size, each of which consists of around 220,000 people, and rural populations. This is similar to the concept of the "garden city" in urban planning, which was examined by Ward (1992). To consider the level of economic development, it should be called "rural city." Apart from metropolitan areas, the construction of rural cities from coast to coast should be the best way to control prefectural government expenditures. However, this may contradict the findings of $\mathrm{Au}$ and Henderson (2006), which showed that more than half of Chinese cities are undersized from the viewpoint of agglomeration effects on workers' productivity. If further migration from rural areas to cities continues to seek higher wages in urban area, it is difficult to maintain the urban population in each prefecture at around 220,000. If the Chinese central or local governments cannot control migration, they should increase tax revenues or find other revenue sources to finance prefectural government expenditures. Recent measures to reform resourcerelated taxation in China are an example of the search for new revenue sources.

Finally, our study has some limitations. First, as we explained in the introduction, we cannot investigate the efficient scales of specific public expenditures such as police and 
fire departments or water supply. If we were able to investigate each type of expenditure, we could consider the assignment of public services among the five layers of government or the efficient structures of local government systems. We could also investigate economies of scale in public expenditures for each item and economies of scope among several types of public expenditure. For example, Drake and Simper (2002) emphasize the existence of economies of scope in public service expenditures. The second remaining problem is a result of the quantile regression approach. The results also shed light on the existence of the large difference in expenditure between governments of similar size but in prefectures with differences in terms of urban or rural populations and area size. This means that some governments spend considerably more than others and some spend considerably less. If we obtain prefectural socioeconomic statistics, which were used by Gyimah-Brempong (1989) to examine the determinants of the cost of providing public safety, we could identify the sources of variation in prefectural expenditures and provide the comparable efficiency ranking within similar size prefectures. However, because we cannot obtain the prefectural governments' expenditures in detail, it remains as an unidentified problem for which prefectural expenditures are inefficient, rural or urban population or area. As for the third remaining problem, because of the data availability, we do not investigate the determinants of the prefectural governments' expenditures in other years. This means that we cannot estimate the historical or dynamic changes in the efficient scale of the prefectural governments. This is also a remaining problem. We should investigate them in the future research. The fourth problem arises from the roles of the prefectural governments in the economic development. ${ }^{10}$ In this paper, we confine all the effects from the performances of the prefectural governments in supporting economic development into the residuals of the regression equation. This problem is crucial for our empirical research, but, at the present stage, we do not have a proper tool to investigate the performances of the prefectural government in economic development. One of the difficulties is that we might not assume profit maximization or cost minimization behavior for the prefectural government. This difficulty prevents us from taking cost function approach to the prefectural government expenditure. We will also try to solve this problem in the future research.

\section{Endnotes}

${ }^{1}$ These population and area data are minimums and maximums in the sample used in this paper.

${ }^{2}$ Some researchers overcome this problem by logarithmic transformation of per capita expenditures and explanatory factors and a quadratic function, which is symmetric around the minimum point.

${ }^{3}$ King and Ma (2000) investigated theoretically the relationship between congestion and the size of local government.

${ }^{4}$ Additionally, Andrews et al. (2002) conducted a literature survey of economies of scale in public education provision.

${ }^{5}$ We consider the total expenditures consisted by these three components, so we cannot identify the effects from rural or urban population size if we consider an interaction term between rural and urban population to capture the effects of economy of scope in public expenditures. In this paper, we do not adopt some interaction terms as explanatory variables. 
${ }^{6}$ One of the referees suggests Rodrik's (1988) finding of a positive correlation between an economy's exposure to international trade and the size of its government. In our paper, we cannot obtain the measure for exposure to international trade for each prefectures

${ }^{7}$ This total expenditure includes budgetary and extrabudgetary expenditures and expenditures of governmental funds in each prefecture.

${ }^{8}$ Winsten (1957) first proposed this method. It is referred to as COLS in the econometrics of efficiency and productivity literature; for example, Fried et al. (2008, p. 35) explains this method.

${ }^{9}$ Chen et al. (2008) proposed the "compact city" for sustainable growth in China, focusing on land saving; thus, it is different from the concept of our "rural city."

${ }^{10}$ One of the referees also pointed that the role of the prefectural government is not supposed only to provide public services, but also to promote local development through promoting local investment to meet financial needs or get political promotion.

Competing interests

The authors declare that they have no competing interests.

\section{Authors' contributions}

YS invited MF in the Department of Economics and Management, Dalian Nationalities University. They discussed on the main ideas of this paper. YS gathered the statistical data and MF conducted econometric works according to YS's explanation about the data and fiscal situations in China. Both authors read and approved the final version of this paper.

\section{Authors' information}

Fukushige is a professor in the Graduate School of Economics, Osaka University. He conducted several researches in applied econometrics and public finance. Shi is an associate professor in Department of Economics and Management, Dalian Nationalities University. He conducted several researches in public finance and public policy.

\section{Acknowledgements}

Shi is grateful to SEAC (2013-GM-022) and DLNU (ZJ13RWYB002) for their financial support of the joint research on this topic with Fukushige. Fukushige is grateful to the Japan Society for the Promotion of Science (Grant-in-Aid for Scientific Research A 23243038 and 15 K12461) for their financial support. The authors are also very grateful for two anonymous referees' comments to clarify the remaining problems of our paper.

\section{Author details}

${ }^{1}$ Graduate School of Economics, Osaka University, 1-7, Machikaneyama-cho, Toyonaka, Osaka 560-0043, Japan.

${ }^{2}$ Department of Economics and Management, Dalian Nationalities University, 18, Liaohe West Road, Jinzhou New Area, Dalian 116600, China.

Received: 21 May 2015 Accepted: 1 January 2016

Published online: 21 January 2016

\section{References}

Ahmad E (1997) China. In: Ter-Minassian T (ed) Fiscal federalism in theory and practice. IMF, Washington, DC, pp 634659

Alesina A, Spolare E (2003) The size of nations. The MIT Press, Boston

Andrews M, Duncombe W, Yinger J (2002) Revisiting economies of size in American education: are we any closer to a consensus? Econ Educ Rev 21(3):245-262

Au C-C, Henderson JV (2006) Are Chinese cities too small? Rev Econ Stud 73(3):549-576

Bahl RW (2011) Intergovernmental fiscal relations and local public finance: what is next on the reform agenda? In: Man JY, Hong Y-H (eds) China's local public finance in transition. Lincoln Institute of Land Policy, Cambridge, pp 247-271

Bahl R, Martinez-Vazquez J (2006) Fiscal federalism and economic reform in China. In: Wallack JS, Srinivasan TN (eds) Federalism and economic reform: international perspectives. Cambridge University Press, Cambridge, pp 249-300

Baleiras RN (2001) To fragment or to consolidate jurisdictions: the optimal architecture of government. FEUNL Working Paper No. 401, Faculdade de Economia, Universidade Nova de Lisboa.

Beaton WP (1974) The determinants of police protection expenditures. Natl Tax J 27(2):335-349

Bodkin RG, Conklin DW (1971) Scale and other determinants of municipal government expenditures in Ontario: a quantitative analysis. Int Econ Rev 12(3):465-481

Borcherding TE, Deacon RT (1972) The demand for the services of non-federal governments. Am Econ Rev 62(5):891-901

Carruthers Jl, Ulfarsson GF (2003) Urban sprawl and the cost of public services. Environ Plann B 30(4):503-522 
Chen H, Jia B, Lau SSY (2008) Sustainable urban form for Chinese compact cities: challenges of a rapid urbanized economy. Habitat Int 32:28-40

Craig SG (1987) The impact of congestion on local public good production. J Public Econ 32:331-353

Craig SG, Heikkila EJ (1989) Urban safety in Vancouver: allocation and production of a congestible public good. Can J Econ 22(4):867-884

Drake L, Simper R (2002) X-efficiency and scale economies in policing: a comparative study using the distribution free approach and DEA. Appl Econ 34(15):1859-1870

Duncombe W, Yinger J (1993) An analysis of return to scale in public production, with an application to fire protection. J Public Econ 52:49-72

Duncombe W, Miner J, Ruggiero J (1995) Potential cost savings from school district consolidation: a case study of New York. Econ Educ Rev 14(3):265-284

Edwards JHY (1990) Congestion function specification and the "publicness" of local public goods. J Urban Econ 27:80-96

Fried HO, Knox Lovell CA, Schmidt SS (2008) Efficiency and productivity. In: Fried HO, Knox Lovell CA, Schmidt SS (eds) The measurement of productive efficiency and productivity growth. Oxford University Press, Oxford, pp 3-91

Gyimah-Brempong K (1989) Production of public safety: are socioeconomic characteristics of local communities important factors? J Appl Econ 4(1):57-71

Hirsch WZ (1959) Expenditure implications of metropolitan growth and consolidation. Rev Econ Stat 41:232-241 Hirsch WZ (1965) Cost function of an urban government service: refuse collection. Rev Econ Stat 47:87-92

Hochman O, Pines D, Thisse JF (1995) On the optimal structure of local governments. Am Econ Rev 85(5):1224-1240

King DN, Ma Y (2000) Local authority size in theory and practice. Environ Plann C: Gov Policy J 18:255-270

Knapp M (1982) Economies of scale in local public services: the case of British crematoria. Appl Econ 14:447-453

Koenker R (2005) Quantile regression. Cambridge University Press, Cambridge

Ladd HF (1992) Population growth, density and the costs of providing public services. Urban Stud 29:273-295

Ladd HF (1994) Fiscal impact of local population growth: a conceptual and empirical analysis. Reg Sci Urban Econ 62: $891-901$

Lichtenberg E, Ding C (2009) Local officials as land developers: urban spatial expansion in China. J Urban Econ 66:57-64

Man JY (2011) Local public finance in China: an overview. In: Man JY, Hong Y-H (eds) China's local public finance in transition. Lincoln Institute of Land Policy, Cambridge, pp 3-17

Martinez-Vazquez J, Qiao B (2011) Assessing the assignment of expenditure responsibilities. In: Man JY, Hong Y-H (eds) China's local public finance in transition. Lincoln Institute of Land Policy, Cambridge, pp 21-40

Nelson MA (1992) Municipal amalgamation and the growth of the local public sector in Sweden. J Reg Sci 32(1):39-53

Oates WE (1972) Fiscal federalism. Harcourt Brace Jovanovich, New York

Rodrik D (1988) Why do more open economies have bigger governments? J Polit Econ 106(5):997-1032

Shelton CA (2007) The size and composition of government expenditure. J Public Econ 91(11):2230-2260

Solé-Ollé A, Bosch N (2005) On the relationship between authority size and the cost of providing local services: lessons for the design of intergovernmental transfers in Spain. Public Finance Rev 33:343-384

Tao HL, Yuan MC (2005) Optimal scale of a public elementary school with commuting costs-a case study of Taipei county. Econ Educ Rev 24(4):407-416

Tsui K (2005) Local tax system, intergovernmental transfers and China's local fiscal disparities. J Comp Econ 33:173-196 Ward S (ed) (1992) Garden city: past, present and future. Routledge, London

Winsten CB (1957) Discussion of Mr. Farrell's paper. J Royal Stat Soc Ser A, Gen 120(3):282-284

World Bank (2007) China: improving rural public finance for the harmonious society, Report No. 41579-CN. World Bank, Washington, DC

\section{Submit your manuscript to a SpringerOpen ${ }^{\circ}$ journal and benefit from:}

- Convenient online submission

Rigorous peer review

- Immediate publication on acceptance

- Open access: articles freely available online

- High visibility within the field

- Retaining the copyright to your article 